\title{
A formação universitária em discurso na rede social Facebook: o que dizem os estudantes de Produção Cênica?
}

\author{
Jean Carlos Gonçalves" \\ Patrícia Pluschkat"* \\ Michelle Bocchi Gonçalves ${ }^{* * * *}$
}

\section{Resumo}

Este texto apresenta alguns resultados de uma pesquisa que buscou compreender os sentidos da formação universitária em Produção Cênica, a partir do que dizem os seus discentes na rede social Facebook. Para tanto, foi escolhido um post, acompanhado dos enunciados presentes na seção de comentários. O aporte teórico-metodológico advém da Análise Dialógica do Discurso, que tem nos estudos de Bakhtin e o Círculo sua principal ancoragem teórica. Os resultados apresentam discursos sobre a formação universitária em Produção Cênica relacionados às preocupações com uma nova área de conhecimento e de trabalho que, em meio às angústias e aos desafios da carreira, precisa estar em sintonia com a esfera cultural na qual está inserida. Outro apontamento relevante é a apropriação da rede social Facebook como meio de interação e interlocução, leitura e escrita, merecendo, portanto, um olhar atento por parte da academia.

Palavras-chave: Formação universitária. Rede social. Análise Dialógica do Discurso.

* Professor dos Programas de Pós-Graduação em Educação (PPGE) e Educação: Teoria e Prática de Ensino (PPGE:Tpen), da Universidade Federal do Paraná. Doutor em Educação (UFPR) com estágio de pós-doutorado no Programa de Estudos Pós-Graduados em Linguística Aplicada e Estudos da Linguagem (LAEL/PUC-SP), sob supervisão de Beth Brait. E-mail: jeancarllos1@bol.com.br

** Produtora Cultural, Graduada em Produção Cênica (UFPR). Mestre pelo Programa de Pós-Graduação em Educação (PPGE/UFPR). E-mail: estrelaflorestilo@ gmail.com

**** Professora da Universidade Federal do Paraná - Setor Litoral. Mestre e Doutoranda no Programa de Pós-Graduação em Educação (PPGE/UFPR). E-mail: michellebocchi@gmail.com

Data de submissão: mar. 2015 - Data de aceite: maio 2015 http://dx.doi.org/10.5335/rdes.v11i1.4866 


\section{Introdução}

A relação entre linguagem e educação vem, há bastante tempo, ganhando espaço em discussões acadêmicas, eventos científicos e importantes textos publicados em periódicos e livros. A proposta que se apresenta por meio deste artigo parte dessa relação, contribuindo para a área ao se debruçar sobre a análise da formação universitária sob o prisma das redes sociais.

Nessa perspectiva, pensar a rede social Facebook como campo de pesquisa se apresenta como uma possibilidade de encontrar, na esfera virtual, novas fontes de leitura e escrita que merecem um olhar atento por parte dos pesquisadores da linguagem e da educação.

Surgem pelas redes, novos modos de ler e escrever, novas maneiras de tecer a invenção de si e do mundo, que não podem ficar alheios aos interesses das pesquisas atuais tanto na área de Letras e Linguística como na área das Ciências Humanas. Nesse ponto, o texto ora apresentado se justifica como possibilidade de se pensar a relação entre "a estante e a vitrine", a partir da exploração da aproximação entre língua e discurso e da inserção das redes sociais no universo do conhecimento linguístico e literário para se compreender outros fenômenos, como, no caso particular desta pesquisa, os sentidos da formação universitária em Produção Cênica.

Este texto tem como objetivo geral apontar perspectivas acerca dos sentidos do curso de Produção Cênica, da Universidade Federal do Paraná, atribuí- dos pelos seus discentes na rede social Facebook. Os objetivos específicos são: analisar criticamente a Produção Cênica na esfera cultural e discutir a formação do profissional Produtor Cênico na esfera universitária, tecendo diálogos com as vozes dos estudantes na esfera virtual.

O texto é composto de três partes: a primeira, consiste da fundamentação teórica, na qual expomos a Análise Dialógica do Discurso e uma discussão acerca da esfera virtual; a segunda contém os procedimentos metodológicos, em um espaço reservado à descrição e contextualização da pesquisa; a terceira parte apresenta a análise dos dados, pela qual é possível lançar um olhar para a materialidade discursivo-enunciativa e refletir sobre os resultados da pesquisa.

\section{Análise Dialógica do Discurso}

Este estudo se fundamenta na Teoria Dialógica ou Análise Dialógica do Discurso. Essa perspectiva de análise tem como pressupostos os estudos de Bakhtin e o Círculo ${ }^{1}$. As obras escritas por esses filósofos consideram a linguagem como um campo expandido, que extrapola os estudos de linguística e literatura, alcançando diversos campos de conhecimento e pesquisa.

Por compreender que as interações sociais são permeadas pela linguagem, e que somos sujeitos constituídos por essas interações, importa a essa pesquisa a compreensão em torno do sentido de 
diálogo, que é explicitada por Bakhtin/ Volochínov (2009), como um processo de interação; a interação por sua vez, é vista vomo como processo de constituição do sujeito e o sujeito como um ser em processo, portanto, em embate com o seu outro.

Segundo Castro (2014), as ideias percorridas nas obras dos pensadores do Círculo de Bakhtin tiveram maior evidência no Brasil ao final dos anos 1970 e desde então, têm sido visitadas e revisitadas em diversos campos, principalmente na área das Ciências Humanas em razão da compreensão acerca da linguagem.

O olhar para a linguagem é o de uma concepção de mundo. Bakhtin/Volochínov (2009) amplia os sentidos considerando-a um fenômeno histórico-social e critica estudos que ainda a atrelam a sistematizações de categorias abstratas das formas normativas. O autor entende a linguagem como um conjunto dos contextos possíveis de uso de cada forma particular, sendo, portanto, viva e heterogênea.

Se as interações humanas e sociais são interligadas à linguagem e essa é vista em seu sentido amplo, isso implica um olhar para o homem e o mundo igualmente generoso. Bakhtin (2011) compreende o mundo como um movimento dialógico e o homem como um sujeito alteritário.

O dialogismo, cerne da teoria bakhtiniana, implica o entendimento da concepção de diálogo como o movimento que ocorre na interação social. Aliás, se refletirmos, a mente do homem não cessa de dialogar. No diálogo com nossas ideias e pensamentos, interagimos com as vozes sociais que compõem a nossa história.
Por isso, é possível afirmar que o homem é, por essência, um sujeito dialógico, mesmo quando não está diante do outro.

Ao nos referirmos ao termo sujeito, é interessante explicar que a interpretação que trazemos a este trabalho é a de que somos sujeitos singulares, entretanto, constituídos por histórias, experiências, relações. E nessas relações, o outro está presente em nossa visão de mundo, nos afetando e nos constituindo.

Isto é, à medida que por meio de interações sociais o outro nos constitui, nos alteramos, enquanto sujeitos, nos construindo e nos transformando pela participação do outro. É o que Bakhtin/ Volochínov (2009) chama de alteridade e é por ela e nela que se organiza a produção de conhecimentos (AMORIM, 2004, p. 105). Tal como nosso processo de construção do sujeito, é o processo de construção da pesquisa. Os conceitos de linguagem, dialogismo e alteridade no viés bakhtiniano foram essenciais para o desenvolvimento desta investigação e a ela estão interligados.

O movimento dialógico como um processo evolutivo é sinônimo de que nada é estático e imutável. O mundo é relacional. E relações implicam em conflitos e deslocamentos.

Assim como a interação entre a linguagem e o mundo, a teoria não se dissocia da metodologia da pesquisa. Nessa linha de pensamento, Amorim (2004) destaca que os métodos e as técnicas de investigação convergem para a questão da alteridade e que a pesquisa é permeada por encontros, encontros com o outro. 
Não conseguimos, portanto, ter uma visão acabada de nós mesmos. Somente o outro pode nos dar uma provisoriedade de acabamento. É o que Bakhtin (2011) chama de excedente de visão. $\mathrm{O}$ que não podemos ver do nosso eu é o que o outro vê. O que o outro não vê de si, é o que nós vemos. São horizontes distintos. Amorim (2004) complementa que não é possível ter uma visão completa do eu, entretanto o olhar do outro nos compõe e nos define.

A pesquisa é permeada por saberes variados que permitem relacioná-la com o mundo, entretanto, no processo do conhecimento científico há métodos que podem auxiliar no direcionamento do pesquisador em sua investigação (CAMPOS, 2009). Ainda assim, não é possível, no campo qualitativo, rechaçar nossos conhecimentos empíricos, pois eles nos constituem, fazem parte de nossa vivência. Somos seres intuitivos, constituídos por experiências. Sendo assim, o método científico dialoga com o empirismo, no quesito da observação, da experimentação e da mensuração.

$\mathrm{Na}$ pesquisa qualitativa (FLICK, 2004), o trabalho tem sido desenvolvido principalmente com textos, sejam coletados via entrevistas, observações, rodas de conversa. $\mathrm{O}$ texto produzido por esses métodos não está isolado de seu contexto e permite uma abordagem de caráter socio-histórico (FREITAS, 2002). Essa perspectiva dialoga com a abordagem bakhtiniana, sendo concebida assim como linguagem viva e como base para a interpretação do pesquisador que nele pode perceber o eco de outras vozes pre- sentes na voz do sujeito que o escreveu, produzindo sentidos.

Ora, tendo como preceito que a linguagem está em constante evolução, por isso a dizemos viva pela lente teórica desta pesquisa, as interações sociais também se desenvolvem permitindo novas formas de relacionamento que constituem diferentes concepções de mundo.

A partir dos estudos de Bakhtin e o Círculo (2011), entendemos que o enunciado é uma unidade real da comunicação discursiva, indissociável do sujeito que o produz e intrinsecamente ligado ao processo de interação social. Ele é constituído pelo seu autor tal como por seus interlocutores e, em uma análise, devem ser considerados todos os seus aspectos históricos, sociais e culturais, pontos de vista e visões de mundo.

Nesse aspecto, podemos refletir que em um enunciado existem enunciações anteriores e posteriores a ele (BRAIT, 2012), o que fundamenta a produção e a circulação de discursos. Os enunciados têm a mesma dimensão das experiências humanas por seu elo com o sujeito e seus valores, com os interlocutores e sua visão de mundo, com os sentidos produzidos.

Dessa forma, o enunciado é marcado por tensões e conflitos, pois ele está no campo das formações ideológicas que alimentam as relações sociais (BAKHTIN/ VOLOCHINOV, 2009). Se uma relação gera tensão, essa tensão causa rupturas e ciclicamente novas tensões. Medviédev (2010) acrescenta que a consciência e a compreensão da realidade ocorrem nas formas de enunciado e não na língua. 


\section{A esfera virtual}

Entendemos, sob a ótica bakhtiniana, que o processo de evolução da linguagem está intrinsecamente relacionado com a sociedade e, assim, com as esferas que a compõem. No mundo virtual, é corrente o termo rede social, que é um lugar no ambiente virtual em que os diálogos também ocorrem e que chamarei, nesta pesquisa, de esfera virtual.

$\mathrm{O}$ surgimento de redes na área da informática advém da evolução comunicacional. Nos estudos de Castells (2000), o autor fala sobre o avanço das redes interativas que desenvolvem uma língua universal digital constituída de palavras, som, imagens - em uma mesma plataforma - formando novas formas de comunicação. Para o autor, esses canais comunicativos moldam a vida, assim como são moldados por ela. Por um olhar bakhtiniano, é possível ampliar a definição do autor, dizendo que os meios comunicacionais constituem e são constituídos pela vida, pois hoje a tecnologia da informação transita por todas as esferas da atividade do ser humano.

Outro ponto abordado por Castells (2000) é que o sistema da rede interativa tem uma comunicação horizontal global. A pensar, a expressão "olhar o horizonte" significa um olhar-além, a uma direção de amplitude inalcançável; a estrutura da rede tem uma abrangência infinita, assim como a atividade humana.

No conto de Jorge Luis Borges, Aleph, publicado no livro de mesmo nome em 1949, é possível traçar uma analogia com os sentidos desse mundo virtual abarcado pelas redes sociais. Na história, a partir do porão de uma casa, o protagonista depara-se com um "ponto do espaço que contém todos os pontos", nisso, podemos dialogar com o conceito de rede compreendido por Martinho (2011) que afirma que ela pertence ao "mundo das ideias" e atravessa espaços e tempos.

O personagem criado por Borges interage com uma variedade de imagens desse universo fantástico - denominado no livro por Aleph - que o constitui. Castells (2000) acrescenta que, na virtualidade, a experiência simbólica por meio da variedade de mensagens é captada transformando-se em experiência humana.

Outro contraponto da obra de Borges é a alteridade do protagonista que inicia a história dizendo que "mudará o universo, mas eu não, pensei com melancólica vaidade", ao se referir à morte de outra personagem do qual não consegue esquecer e termina questionando "nossa mente é porosa para o esquecimento; eu mesmo estou falseando e perdendo, sob a trágica erosão dos anos, os traços de Beatriz". Podemos pensar em uma correlação com o pensamento bakhtiniano de que as redes sociais são interações que nos alteram e nos constituem por meio da linguagem virtual.

A rede, quando compreendida como um processo organizacional que pode ser formado por pessoas ou instituições ou entidades, que se reúnem com propostas em comum, também tem interações horizontais (MARTINHO, 2011). O autor cita o físico Fritjof Capra para justificar sua 
perspectiva fazendo um paralelo de que, como organismos vivos, também estamos conectados em rede: células se conectam formando um tecido, tecidos são compostos por neurônios que por sua vez estão interligados a outros neurônios.

Martinho (2011) acresce em sua perspectiva que a comunicação horizontal das redes se contrapõem à hierarquia, o que faz com que nesse âmbito existam muitas lideranças, não somente uma, gerando conflitos, pensamento que vai de encontro com as ideias de Bakhtin e o Círculo no tocante às relações sociais mediadas pela linguagem, que também são conflituosas.

Se por um lado em uma rede social estão todos conectados sem uma figura de liderança, nao podemos negar que os discursos publicados são constituídos por juízos de valor.

O cantor e compositor Zeca Baleiro, em seu livro que reúne crônicas publicadas na coluna Última Palavra, da Revista IstoÉ, faz a seguinte alusão relacionada a essa questão:

De todas as ilusões que a Internet alimenta, a que julgo mais grave é a terrível onipotência que seu uso desperta. Todos se acham capazes de tudo, com direito a tudo, opinar, julgar, sugerir, depreciar, mas sempre à sombra da marquise, no confortável "anonimato público" que o mundo paralelo da rede propicia (BALEIRO, 2014, p. 47).

Já, Castells (2000) defende que a ideia de rede é a de contribuição mútua, tendo cada indivíduo sua própria voz. $\mathrm{O}$ problema dessa concepção é que, como sujeitos alteritários, somos construídos e constituídos pelo outro (BAKHTIN,
2011), então, mesmo como indivíduos únicos, nossa voz social carrega a percepção de mundo do outro. Nossos discursos não são inéditos.

A rede social Facebook foi criada em 2004 pelos então estudantes, na época, da Universidade de Harvard (EUA): Mark Zuckerberg, Eduardo Saverin, Dustin Moskovitz e Chris Hughes. Castells (2000), ao informar em sua obra sobre as primeiras redes sociais, que tiveram origem no campo universitário, apresenta o seguinte ponto de vista:

[...] as universidades são os principais agentes de difusão de inovações sociais porque geração após geração de jovens por ali passam, ali conhecem novas formas de pensamento, administração, atuação e comunicação e se habituam a elas (CASTELLS, 2000, p. 380).

Castells (2000) incita que inicialmente as redes sociais estavam restritas a um grupo de usuários que a utilizavam como um hobby. O Facebook iniciou denominado Thefacebook, pois coincidia com a denominação de um livro que era entregue aos alunos no início do ano letivo em algumas universidades dos Estados Unidos, no intuito dos discentes conhecerem um pouco uns dos outros. Assim, a rede também tinha essa função de interação entre os estudantes, por ser restrita à esfera universitária, primeiramente em Harvard e logo sendo uma ideia expandida a outras universidades.

Foi somente em setembro de 2006 que o Facebook passou a abranger um público geral independente da esfera em que os sujeitos se situassem. Um ano 
após essa abertura pública, o mercado passou a integrar a rede utilizando-a como ferramenta de marketing.

$\mathrm{O}$ alcance desse meio social foi gradativo e em 2010, devido a um acordo com a operadora de telefonia móvel Tim, o Facebook também ganhou espaço nos aparelhos celulares. Canclini (2008, p. 39) observa em seus estudos sobre cultura um comparativo entre o relógio e o aparelho celular. $\mathrm{O}$ autor cita Julio Cortázar ao refletir que um relógio é "um pedaço frágil e precário de você mesmo" e que, atualmente, não há a necessidade de um relógio de pulso graças ao invento dos telefones celulares.

Segundo o autor, o corpo é um portador da cultura (basta observarmos o vestuário, a pintura, as posturas), assim, as novas tecnologias passam a integrar o corpo como parte da indumentária. Canclini ainda afirma que

[...] para os jovens, torna-se um recurso para novas experiências corporais e de comunicação. Mais do que a localização, importam as redes. Mesmo sentado, o corpo atravessa fronteiras (2008, p. 44).

Com o acesso à rede acontecendo em tempo facilitado, em 2012, o uso do $F a$ cebook no Brasil ultrapassou o de outras redes como o Orkut ou o Twitter. Outro meio de comunicação virtual que vem ganhando destaque é o whatsapp, um aplicativo de "bate-papo" utilizado em aparelhos celulares e que desde 2014 pertence à empresa do Facebook.

A estrutura da rede social do Facebook é formada por um perfil em que o usuário constrói sua persona divulgando uma foto de identificação e dados pessoais como data de nascimento, cidade em que reside, status de relacionamento. Essa identidade virtual cria uma rede de relacionamentos com determinadas pessoas e/ou grupos que terão acesso às informações de seu perfil, conforme suas configurações na rede social.

Uma das formas de aumentar nossa rede de amizade é quando um amigo nos apresenta a outro amigo, conectando-nos uns aos outros, e assim, a rede é tecida sucessivamente (CASTELLS, 2000). No Facebook, a própria rede indica uma relação de possíveis amigos, compondo relações de forma dinâmica e veloz.

$\mathrm{O}$ "eu" criado para a rede social pode ser comparado a um personagem, pois nós não temos uma visão completa de nós mesmos. Bakhtin questiona:

Quantos véus necessitamos tirar da face do ser mais próximo - que nela foram postos pelas nossas reações casuais e por nossas posições fortuitas na vida -, que nos parecia familiar, para que possamos ver-lhe a feição verdadeira e integral. A luta do artista por uma imagem definida da personagem é, em um grau considerável, uma luta dele consigo mesmo (BAKHTIN, 2011, p. 04).

Somos autores desses personagens que descrevemos, de acordo com a multiplicidade de vozes que nos constituem. "[...] o autor acentua cada particularidade da sua personagem, cada traço seu, cada acontecimento e cada ato de sua vida, os seus pensamentos e sentimentos, da mesma forma como na vida nós respondemos axiologicamente a cada manifestação daqueles que nos rodeiam [...]" (BAKHTIN, 2011, p. 03).

Também faz parte da estrutura da rede, um mural em que é mostrado o feed de notícias, que é uma lista de atualiza- 
ções dos amigos interligados na rede com as postagens que publicam: o que estão fazendo? o que estão pensando? Aqui, o personagem também é espectador.

As publicações no feed de notícias acontecem pela atualização de status, palavra que remete a prestígio social. As pessoas que têm status tendem a ser seguidas como modelos, formadores de opinião e influenciam um público específico de sua esfera.

$O$ recurso permite que os usuários da rede comuniquem o que lhes interessa. Isso tem gerado algumas críticas entre os próprios usuários da rede, pois a exposição de determinado usuário nem sempre agrada ao outro. E o intuito não parece ser o de agradar ao outro, mas sim de buscar uma aceitação (ou prestígio) do outro. Bakhtin esclarece essa necessidade de interação inerente ao ser humano da seguinte maneira:

Nesse sentido pode-se dizer que o homem tem uma necessidade estética absoluta do outro, do seu ativismo que vê, lembra-se, reúne e unifica, que é o único capaz de criar para ele uma personalidade externamente acabada; tal personalidade não existe se o outro não a cria; a memória estética é produtiva, cria pela primeira vez o homem exterior em um novo plano da existência (BAKHTIN, 2011, p. 33).

Nossos atos são realizados para o outro e para que o outro aprove, desaprove, dialogue, por meio de uma atitude responsiva. Podemos pensar, na perspectiva de Bakhtin, que essa responsividade é no sentido de sermos responsáveis pelos nossos atos ao mesmo tempo em que o fazemos em resposta ao outro.
Em nosso cotidiano, a palavra do outro constitui nossa concepção de mundo. Basta observar quantas vezes ouvimos em conversas informais expressões "como diz o fulano" "fulano me disse" (Bakhtin, 2010). Desta forma, a palavra do outro está presente em nossa vida de maneira tal que, segundo Medviédev (2010), não há um álibi para a atitude humana, por isso somos éticamente responsáveis por nossos atos.

$\mathrm{O}$ que acontece é que por meio da rede social essa necessidade do outro ganhou maior visibilidade. Para Canclini (2008, p. 54), as redes virtuais "alteram os modos de ver e ler, as formas de reunir-se, falar e escrever, de amar e saber-se amado à distância [sic], ou, talvez, imaginá-lo".

Fazem parte também da estrutura do Facebook: mensagens privadas, criação de eventos, calendário, aplicativos de jogos, reprodução de vídeos e linha do tempo.

Aqui cabe uma análise no que se refere à linha do tempo (timeline). $\mathrm{O}$ perfil de cada usuário do Facebook apresenta uma timeline. Nela, as publicações de fatos cotidianos permitem a permanência de uma memória virtual na rede social, uma vez que o cotidiano postado está ali, fixo naquele espaço-tempo. Uma vez registrado, aquele momento factual passa a ser visto e revisto por quem quiser - e tiver a permissão do usuário. A linha do tempo é tecida por status em sua maioria formados por enunciados e imagens.

Esses status publicados na linha do tempo e vistos no feed de notícias são complementados, ainda, por três botões: o curtir, o comentar e o compartilhar, 
com os quais outros usuários podem interagir. $\mathrm{O}$ primeiro botão é acionado quando o outro concorda com determinado posicionamento. Novamente podemos refletir no conceito de atitude responsiva de Bakhtin: enquanto sujeitos alteritários esperamos ou antecipamos uma resposta do outro. $\mathrm{O}$ segundo botão permite a postagem de novos enunciados a partir do primeiro travando um diálogo, e o terceiro botão, possibilita que aquela opinião/exposição seja partilhada a outros usuários.

No que o acionamento desses botões implica? O curtir, em aceitação, o comentar em opinião e o compartilhar em propagação. Entretanto, todos podem ser considerados como possibilidade de diálogo.

Em 2011, o Brasil aparece em quarto lugar no ranking dos países que mais utilizam a rede social Facebook. Assim, alguns questionamentos podem ser feitos para repensar sobre esse meio de comunicação: publicações em redes sociais podem ser vistas como um gênero discursivo? Com quem ou com o quê os sujeitos que utilizam essas ferramentas dialogam? Que vozes ecoam nesses enunciados?

No primeiro ponto, buscamos em Bakhtin uma possível resposta. Considerando que a linguagem das redes sociais foi um estilo peculiar tendo termos criados e re-criados a cada publicação virtual, Bakhtin afirma que:

A riqueza e a diversidade dos gêneros do discurso são infinitas porque são inesgotáveis as possibilidades da multiforme atividade humana e porque em cada campo dessa atividade é integral o repertório de gêneros do discurso, que cresce e se diferencia à medida que se desenvolve e se complexifica um determinado campo (BAKHTIN, 2011, p. 262).
Sob a mesma perspectiva teórica, compreendemos que existem diálogos nas postagens do Facebook, mesmo quando é o silêncio que produz sentidos. Brait (2005) explana que as palavras estão carregadas de valores e, quando enunciadas, são avaliadas por seus interlocutores. Compreendidas, podem receber como ato o silêncio do interlocutor, mas, como afirma Bakhtin (2011), em um determinado momento, será respondida em outros discursos ou em outra forma de atitude pelo interlocutor ouvinte. Assim, um enunciado publicado pode obter comentários escritos e visuais, mas também receber a ação do outro sujeito quando esse opta por acionar os links: curtir, comentar ou compartilhar.

Também ponderamos que se um post não obteve nenhuma ação como curtir, comentar ou compartilhar, isso pode indicar não somente uma falta de concordância com o enunciado e o seu autor, mas também um receio de comprometimento com a exposição de sua opinião, ou uma concordância parcial, ou, ainda, uma postura do sujeito que acredita dispensável mostrar uma opinião assertiva ou não para o público virtual.

O próprio falante está determinado precisamente a essa compreensão ativamente responsiva: ele não espera uma compreensão passiva, por assim dizer, que apenas duble o seu pensamento em voz alheia, mas uma resposta, uma concordância, uma participação, uma objeção, uma execução, etc. (os diferentes gêneros discursivos pressupõem diferentes diretrizes de objetivos, projetos de discurso dos falantes ou escreventes) (BAKHTIN, 2011, p. 272). 
Esse diálogo diferenciado, também denominado como interatividade, é abordado por Canclini (2008, p. 53) na assertiva de que

[...] mesmo em línguas diferentes, a fala e a escrita dos jovens caracterizam-se por modulações linguísticas compartilhadas, apresentam códigos estilísticos e de auto-reconhecimento semelhantes.

Ainda em relação à linguagem, Castells (2000) aponta que existe um contraponto entre teóricos, enquanto alguns acreditam que a linguagem virtual seja um novo meio escrito, a exemplo da tipografia de Gutemberg, por se tratar de um discurso que permite ser registrado, semelhante ao que se faz em livros - a tradução literalda palavra Facebook, é "cara de livro" - outros o apontam como uma nova forma de oralidade por se tratar de um texto espontâneo e informal com diálogos em tempo real. Castells defende uma fusão de ambas as teorias e aposta em uma nova forma de comunicação.

Bakhtin (2011), ao explanar sobre os gêneros do discurso, esclarece que os enunciados estão interligados a uma esfera, refletindo uma temática e um estilo - indissociáveis - peculiar de cada campo. Há uma variedade inesgotável de gêneros do discurso, pois a atividade humana não é estática, assim à medida que as esferas sociais se desenvolvem, surgem novas possibilidades de diálogos.

De acordo com o autor, os gêneros, tanto orais quanto escritos, se dividem em primários, que abarcam os discursos cotidianos, e secundários, cujas produções são mais complexas por se tratar de códigos culturais desenvolvidos por sistemas específicos (teses científicas, gêneros publicitários, etc.) Mas isso não é categórico, pois ambas as esferas podem se complementar e assim, se modificar.

No Facebook, a linguagem que observamos é a de um diálogo cotidiano. Vemos imagens e lemos textos que expõem o dia a dia da vida de cada usuário contando a tessitura de suas histórias. Também, opiniões a favor ou contra assuntos polêmicos fazem efervescer a timeline em períodos decisivos ou de grandes acontecimentos. É um espaço-tempo de diálogos como também uma circulação de conhecimentos heterogêneos.

A exemplo do que afirma Bakhtin (2011), como expus no parágrafo anterior, a partir do momento em que utilizo enunciados de um gênero primário, Facebook, para analisá-los em um texto acadêmico, ambos se alteram.

A quem as postagens se destinam? A priori, aos que também utilizam desse instrumento de comunicação e recorrem ao mesmo estilo linguístico. Entretanto, os enunciados têm sempre uma temática abordada. Então, o diálogo destina-se aos que queiram opinar a respeito do assunto abordado.

Eu vivo em um mundo de palavras do outro. E toda a minha vida é uma orientação nesse mundo; é reação às palavras do outro (uma reação infinitamente diversificada), a começar pela assimilação delas (no processo de domínio inicial do discurso) e terminando na assimilação das riquezas da cultura humana (expressas em palavras ou em outros materiais semióticos) (BAKHTIN, 2011, p. 370). 


\section{Procedimentos metodológicos}

A pesquisa foi realizada tendo como sujeitos colaboradores, os discentes do curso de graduação em Produção Cênica da Universidade Federal do Paraná - Curitiba/Brasil, que integraram as turmas ingressantes de 2009 a 2012. Em 2013, o curso passou por uma mudança curricular significativa, o que ocasionou a mudança de sua estrutura, justificando um recorte temporal no corpus de análise.

A referida graduação teve origem em 2009, a partir de uma demanda do Reuni (Plano de Reestruturação e Expansão das Universidades). Anteriormente, a Universidade Federal do Paraná contava com o curso Técnico em Artes Cênicas, que abriu sua primeira turma no ano de 1998, no extinto Setor Escola Técnica, e tinha claro direcionamento para a formação de atores. Sua origem está atrelada à Companhia de Teatro da UFPR - Palavração, e desemboca na criação do Curso Superior de Tecnologia em Produção Cênica. Esse novo curso é alocado no Setor de Educação Profissional e Tecnológica da Universidade Federal do Paraná, tendo sua primeira oferta de vagas no primeiro semestre de 2009, no período noturno, com duração total de três anos, carga horária total de 1800 horas/aula e oferta de 45 vagas anuais.

O Catálogo Nacional dos Cursos Superiores de Tecnologia, lançado pelo Ministério da Educação em 2006, aloca o Curso Superior de Tecnologia em Pro- dução Cênica na grande área de Produção Cultural e Design, e descreve como atribuições do curso:

O tecnólogo em Produção Cênica atua na produção de espetáculos que envolvem música, dança, apresentação, cinema, vídeo e teatro. Este profissional trabalha com tecnologias, linguagens e propostas estéticas. Realiza projetos para captação de recursos e atividades de planejamento, execução e divulgação de eventos e espetáculos. São características desse tecnólogo: conhecimento histórico-interpretativo das artes cênicas e domínio de códigos, convenções, legislação de incentivo cultural e técnicas dessas linguagens específicas (BRASIL, 2010, p. 89).

No seu surgimento, o curso contava com um currículo bem direcionado às artes cênicas, especificamente ao teatro, contando com uma série de disciplinas voltadas à formação de atores. Em 2010, foi aprovado o primeiro ajuste curricular, por meio do qual a carga horária das disciplinas diminuiu consideravelmente, em um esforço do corpo docente no sentido de privilegiar áreas que pudessem atingir as expectativas de um Curso Superior de Tecnologia em Produção Cênica, como descrito pelo catálogo do MEC.

Para compreender o que dizem os discentes do curso sobre essa formação universitária, recorremos à rede social Facebook, que é, hoje, uma das mais conhecidas e utilizadas redes sociais no Brasil. Ao acessar o Facebook, ainda no início do estúdio, nos deparamos com uma variedade de enunciados postados pelos discentes do curso de Produção Cênica, constituídos de sentidos sobre suas experiências na universidade, e suas relações com o próprio curso, com 
as expectativas de trabalho e com a vida pós-universidade. Ao perceber a possibilidade de analisar os enunciados publicados na rede social Facebook, realizamos um estudo exploratório no $2^{\circ}$ semestre de 2013, momento em que pudemos apurar que os sentidos produzidos poderiam integrar e construir esta pesquisa.

Primeiramente, dos 204 estudantes das quatro primeiras turmas de Produção Cênica, acessamos os perfis virtuais de 127 usuários da rede social, descartando do corpus da pesquisa os desistentes do curso ou os que não têm perfil no Facebook. Examinamos todas as publicações desde $o$ ano em que os alunos ingressaram na Universidade - primeira turma, em 2009 - até o ano em que realizamos o estudo exploratório, 2013.

Utilizamos como critério de seleção os enunciados que se ativeram ao curso de Produção Cênica e aos graus de expectativas relacionados a ele e à profissão do produtor cênico. Mesmo que as publicações no Facebook sejam, em sua maioria, acessíveis ao público, ou pelo menos a um público restrito (os amigos), enviamos aos colaboradores da pesquisa uma solicitação de autorização para uso dos enunciados na pesquisa. Essa autorização foi enviada via mensagem inbox (privada) do Facebook e dos 127 estudantes, 56 permitiram o uso de suas publicações para fins acadêmicos.

Desses 56, três posts, acompanhados de seus comentários, integraram a totalidade da análise, sendo que um deles compõe a materialidade discursivo-enunciativa deste artigo. O critério de escolha desse enunciado justifica-se pela abrangência temática atribuída à formação universitária pelo seu autor e ao movimento dialógico presente na troca de enunciados que compõem os comentários.

\section{Análise e resultados}

Post Sujeito 1: Conclusão sobre a aula: É realmente difícil ser produtor cultural em Curitiba. Não basta só ter vontade de fazer algo, tem que escrever direito, tem que ter bons contatos profissionais e o mais confuso e difícil é: começar. É isso mesmo Produção.

07 de maio de 2013

12 curtidas 7 comentários

Comentário Sujeito 2: Nem me fale... 07 de maio de 2013

0 curtida

Comentário Sujeito 2: Mas vamos lá, que 10 minutos de carreira não é nada, né?

07 de maio de 2013

1 curtida

Comentário Sujeito 3: e não dizer coisas que te façam parecer preconceituoso em mesas-redondas

07 de maio de 2013

2 curtidas

Comentário Sujeito 4: É difícil ser humano em Curitiba com todos esses atributos, quem dirá artista

07 de maio de 2013

1 curtida 
Comentário Sujeito 5: E ainda tem a parte que o sucesso começa incomodar, as máscaras cair...

07 de maio de 2013

0 curtida

Comentário Sujeito 1: Até o sucesso chegar, lá se foram uns 10 ou 15 anos hein...

07 de maio de 2013

2 curtidas

Comentário Sujeito 2: Trabalho + muito trabalho + estudo e um bocado de sensibilidade trazem reconhecimento $e$ por consequência o famigerado sucesso... (e bota a comida na mesa né, gente)

07 de maio de 2013

1 curtida

A linguagem dos enunciados dessa seção se mistura entre o universo acadêmico e um bate-papo informal acerca da profissão do produtor cênico. O Sujeito 1 incita quase que uma provocação em seu enunciado: analise, debata, dialogue! Para que outros interajam mediante sua reflexão. Os demais interlocutores aceitam o desafio e rebatem com todos os tipos de opinião. Bakhtin/Volochinov (2009) afirmam que é no contexto social que se determinam seus possíveis ouvintes: amigos ou inimigos.

O Sujeito 1 vivenciou um fato que lhe afetou de maneira tal que ele teve $o$ desejo de compartilhar em seu mural do Facebook. Ele inicia o enunciado com a sentença: "Conclusão sobre a aula:" como se isso pertencesse ao campo "assunto" de um e-mail ou de um documento formal.
A palavra "conclusão" dá o tom de que o assunto está encerrado. Mesmo que alguém possa pensar que as reflexões sobre as aulas do ensino superior são inesgotáveis o tom enunciativo está dado.

Após as primeiras palavras, ao utilizar a sinalização dois pontos, ele indica que irá enunciar algo que acaba de acontecer. Ele reafirma isso com a frase que antecede ao sinal, "Conclusão sobre a aula". Após assistir a aula de uma determinada disciplina do curso, o aluno chega a uma compreensão. Essa nova compreensão sucedida na sala de aula só é possível porque somos sujeitos constituídos pelas interações. Ghelli complementa o pensamento em relação ao aprendizado quando afirma que:

[...] podemos entender aprendizagem como mudanças que ocorrem no comportamento de uma pessoa em função de experiências e vivências. A aprendizagem na aula universitária pode ser verificada no momento em que ela termina e o aluno tem a sensação de que construiu, descobriu, acrescentou algo na sua forma de pensar e ver determinada situação (GHELLI, 2004, p. 06).

O aluno pôde ter um olhar mais apurado em relação ao seu futuro profissional e, a partir, da aula percebe que sua dúvida em relação às dificuldades da futura profissão passou a ser uma assertiva. Essa possibilidade é apreendida em suas palavras posteriores ao sinal de dois pontos em que é dito "é realmente difícil ser produtor cultural em Curitiba" e reforçado com o adjunto adverbial de afirmação "realmente". É possível identificar o eco de outras vozes no enunciado, afinal, esse conflito com a profissão e com a cidade foi vivenciado 
na esfera universitária, na qual há uma pluralidade de vozes produzidas por discursos e discursos de discursos que reverberaram no discurso do discente.

É possível que esses discursos no curso refratem as vozes de profissionais que atuam no mercado de trabalho cultural da cidade, quando esses levam suas experiências à universidade, assim como refletem nos discentes que anseiam em pertencer a esse mercado de trabalho. Por que é difícil ser Produtor Cênico? Por que especificamente na cidade de Curitiba? É possível que essa tensão ocorra porque essas vozes sociais, de atuantes da esfera de produção cultural, atuam ou tentam atuar no mercado de trabalho da capital paranaense sem êxito, visto que é um campo profissional relativamente recente.

Buarque (1993) defende que uma universidade está intrinsecamente ligada à sua localização geográfica. $\mathrm{O}$ ponto positivo é que a universidade toma seu compromisso com o meio e ambos se beneficiam, entretanto, corre-se o risco de cair no regionalismo e no provincianismo, ignorando o resto do mundo. No Projeto Pedagógico do curso de Produção Cênica há um discurso otimista em relação ao mercado de trabalho do produtor teatral na região, como se pode ler:

É grande o número de festivais de teatro, mostras artísticas, oficinas, editais de fomento às artes circenses e operísticas, produzidos e/ou sediados no perímetro compreendido pela capital paranaense e sua região metropolitana (BRASIL, 2012. p. 2).

É possível observar espaços para novos acontecimentos culturais, mas quais poderiam ser as adversidades? De um lado, apesar dos incentivos fiscais, ainda é difícil no país conseguir verbas para as produções culturais. De outro, com o processo de globalização, o mercado ganhou uma nova dimensão, na qual incidem as expressões culturais.

Podemos, aqui, recorrer aos conceitos de forças centrípetas e centrífugas propostos por Bakhtin. Ao compararmos as produções teatrais de produtoras que não estejam no alcance midiático ou que estejam em processo de início de carreira em seus trabalhos, com produtoras famosas, é possível que essas grandes produtoras fiquem no centro das atenções dos festivais/editais/patrocinadores e à margem, localizamos as demais produções. Mesmo com festivais locais, a hegemonia do centro leva vantagens e predominam as produções do eixo Rio de Janeiro/São Paulo.

$\mathrm{O}$ que presenciamos hoje são artistas de renome internacional conquistando aprovação do Estado para captação de verbas públicas que poderiam ser investidas em ações culturais desenvolvidas por produções heterogêneas. No Dicionário Crítico de Política Cultural, Coelho (1997) provoca ao falar de incentivo cultural:

[...] as produções iniciais feitas ao abrigo da lei deixaram muito a desejar devido à falta de critérios claros sobre o que poderia ser considerado artístico ou cultural, ponto nodal da questão (num primeiro momento da existência dessas leis, multiplicaram-se os livros ditos "de arte", com muita ilustração e pouco texto e feitos para servirem de brindes institucionais de fim de ano). Aos poucos deu-se uma reorientação das aplicações dos incentivadores, que passaram a apoiar produtos de maior valor cultural, como filmes, espetáculos teatrais e musicais (COELHO, 1997, p. 214). 
Outro impasse, além da conquista de verbas, é a conquista do público. Essas grandes produções são valorativas perante uma plateia acostumada com a exposição dos artistas na mídia. Em contrapartida, o que tem surgido são produções exibidas na internet como um possível caminho para que os pertencentes à margem continuem nessa fronteira e, entretanto também possam ganhar valor de reconhecimento.

Mas nosso sujeito em questão mostra-se apreensivo com a produção artística em sua cidade, Curitiba. A capital ganhou fama, por meio de uma estratégia de $m a-$ rketing, de ser consumidora exigente. Assim como o discurso do outro nos constitui como sujeitos, discursos criados para fins distintos também acabaram constituindo um perfil cultural da cidade que pode ser entendido segundo Eagleton:

Pessoas que pertencem ao mesmo lugar, profissão ou geração nem por isso constituem uma cultura; elas o fazem somente quando começam a compartilhar modos de falar, saber comum, modos de proceder, sistemas de valor, uma autoimagem coletiva (EAGLETON, 2011, p. 59).

Assim como a cidade, os curitibanos também são conhecidos por discursos estereotipados, construídos a partir de uma noção de identidade regional como um povo culto e intelectual, por isso, críticos e exigentes e reverberando no imaginário dos que estão externos a esse grupo social elitizado como um povo frio, fechado, antipático e exigente ${ }^{2}$. $\mathrm{O}$ Sujeito 4 reforça essa reflexão ao enunciar no comentário "É difícil ser humano em Curitiba, com todos esses atributos, quem dirá artista”. No entanto, pelos estudos de Bakhtin (2011), é preciso esforço para conseguimos imaginar nossa imagem externa. Bakhtin/Volochinov reitera:

Se algumas vezes temos a pretensão de pensar e de exprimir-nos urbi et orbi, na realidade é claro que vemos "a cidade e o mundo" pelo prisma do meio social concreto que nos engloba. Na maior parte dos casos, é preciso supor, além disso, certo horizonte social definido e estabelecido que determina a criação ideológica do grupo social e da época a que pertencemos, um horizonte contemporâneo da nossa literatura, da nossa ciência, da nossa moral, do nosso direito (BAKHTIN, 2009, p. 116).

Prosseguindo a análise do enunciado, o discente assinala que é preciso mais do que a "vontade" de realizar produções culturais. E o que é ter "vontade"? Estar inserido num curso universitário? Se dedicar aos estudos? Tentar se inserir no mercado de trabalho? Ao utilizar o advérbio "só", que nesse caso tem um valor restritivo, ele assume que essa "vontade", essa ânsia, esse desejo não são suficientes.

Como sujeito discente, o estudante percebe que ter atributos específicos lhe darão subsídios como profissional. No contexto universitário, esses subsídios podem ser incentivados na sala de aula. De acordo com o Projeto Pedagógico do curso de TPC, há um estímulo para as aulas de campo, que são realizadas em teatros, estúdios, produtoras entre outros locais relacionadas com a área. Ghelli (2004, p. 01) afirma que 
[...] o papel da universidade em uma democracia deve não somente incentivar a reprodução, mas também a produção de conhecimentos, bem como qualificar as novas gerações para a vida e o trabalho.

De outro modo, se a Universidade tem um papel substancial na formação do profissional, o estudante reconhece sua parcela de compromisso. A expressão modalizadora "tem que" indica normas, regras. Faz pensar em uma maior responsabilidade e obrigatoriedade para com saberes distintos.

E para iniciar o rol de deveres do produtor, o discente assinala que é preciso "escrever direito". Mas, afinal, o que é escrever direito? É escrever de acordo com as normas linguísticas? Escrever de acordo com que os outros querem ler? Em nosso cotidiano utilizamos "linguagem informal" para nos comunicar, entretanto, ao submetermos textos para determinadas esferas, a linguagem se modifica. Para projetos culturais, por exemplo, o gênero discursivo tem um estilo formal e objetivo composto por regras a serem seguidas que reverberam num texto marcado por formalidade.

Um grupo artístico tem seus valores ao criar um espetáculo, todavia, esse pode acabar restrito às diretrizes de festivais/editais. A escrita de um projeto, assim como outras escritas, tem um interlocutor. O discurso cênico é direcionado a tais interlocutores, de forma a criar uma empatia e cativar seus leitores. Se não limitarmos a comunicação artística à linguagem escrita, também podemos olhar para esse "escrever direito" por seu lado estético:
A arte é uma forma de comunicação. [...] A característica da arte é sua conotação estética. Ela comunica-se de uma maneira mais densa e concentrada do que experimentamos na vida cotidiana. Também o local ou contexto em que a comunicação artística acontece indicam que alguma coisa especial está ocorrendo (SMIERS, 2006, p. 121).

Mais uma atribuição do produtor, segundo o autor do enunciado, é que o profissional precisa "ter bons contatos profissionais". Atualmente, o curso não tem em sua grade o estágio obrigatório. Mesmo apoiando a realização de estágios no campo da produção cênica, o fato de não ser uma disciplina obrigatória pode indicar a dificuldade da abertura de contatos profissionais da área, de acordo com o reclame do discente.

A discussão em torno da dicotomia teoria versus prática na Educação é um caminho a ser alinhado, afinal o próprio conceito de curso tecnólogo é uma alternativa para que exista uma unidade. De acordo com Ghelli:

A relação entre teoria e prática deverá ser o fim a que propõe o professor, pois toda teoria começa com a prática, e ela é uma tentativa de explicar uma prática, ou seja, uma não existe sem a outra. A teoria não deve ser uma mera contemplação, mas guia de uma ação. A prática também não deve ser mera aplicação da teoria, mas deve ser vista como a própria ação guiada e mediadora da teoria (GHELLI, 2004, p. 08).

Entretanto, o enunciado também evidencia a importância do outro em sua esfera profissional por meio da interação social. É esse movimento de alteridade que constitui o sujeito e permite que $o$ homem faça e refaça suas escolhas como 
um ser inacabado, se permitindo a uma composição de ideias e atos.

Ora, relações sociais são indispensáveis em qualquer campo. Na esfera de produção cultural, Oliviere e Natale (2010) também orientam a relevância das parcerias no meio cultural.

Outro ponto importante, óbvio até, mas que muitos esquecem no desenvolvimento de projetos, é o conceito de parceria. É bom não esquecer que parceria deve significar um conjunto de pessoas que se agrupam para atingir interesses comuns. Assim, a clareza é um pressuposto fundamental. Além disso, a comunidade em que o projeto está sendo apresentado também deve ser considerada parceira, e não receptora compulsória do projeto (OLIVIERE \& NATALE, 2010, p. 23).

No enunciado, o estudante também afirma estar confuso, principalmente por achar que o mais custoso da profissão é "começar". Esse verbo infinitivo sugere o agir, o dar início a um processo, o estopim para um percurso. Afinal, por onde começar? No ponto de vista axiológico do sujeito, esse impulso inicial, o sair da aparente inércia é como ir de encontro ao caos. $\mathrm{O}$ estudante acredita que seu conhecimento em relação à futura profissão é parco. $\mathrm{E}$ é possível que o caos instalado em seu consciente se faça porque o discente está em seu último ano na faculdade.

Sempre que nos lançamos ao novo, sentimos a dificuldade da ação inicial, Cunha \& Zanchet (2010, p. 192) alertam que "o início de uma profissão inclui o reconhecimento de sua cultura, do estatuto que ocupa na pirâmide social e do trabalho e das peculiaridades sociopolíticas que a caracterizam".
Ao fim do enunciado, o estudante pede uma atitude responsiva "é isso mesmo Produção”, expressão recorrente entre os discentes de TPC. Há uma alternância de sujeitos nesses enunciados, seus interlocutores são seus colegas do curso de TPC e é com eles que esse sujeito incita o diálogo. E como todo ato implica uma resposta, o discente recebe comentários em sua publicação em concordância com seu discurso.

Observamos que os comentários de seus colegas foram empáticos com a problemática do autor. Bakhtin (2011) valida que "cada enunciado é um elo na corrente complexamente organizada de outros enunciados" (BAKHTIN, 2011, p. 271). "Nem me fale" pode ser reconhecido com um enunciado de aprovação, de um sujeito que sabe bem o que o autor do post está querendo dizer. O mesmo Sujeito 2 faz um novo comentário que parece indicar uma ironia em relação a algum dos temas tratados em aula "10 minutos de carreira não é nada, né?. Esse tom irônico aparece também no comentário do Sujeito 3. Para Brait (2008, p. 14), a ironia pode ser investigada como o "resultado de um conjunto de procedimentos discursivos que pode aparecer em não importa que tipo de texto". Não é possível saber, sem conhecer a esfera de produção dos discursos citados indiretamente nesses enunciados, o teor exato da discussão, já que os autores dos enunciados em questão fizeram parte de um evento enunciativo (a aula) da qual nós, pesquisadores-analistas, não participamos. 
No entanto, é importante perceber a maneira como o discurso vai se encaminhando até que o sucesso entre em cena na voz do Sujeito 5 e é retomado na voz do Sujeito 1. Destacamos aqui a preocupação com o mercado de trabalho, que é ressaltada na ideia de sucesso como único meio de realização profissional. A palavra sucesso pode ser vista nos enunciados como uma marca ou pista linguística para que possamos depreender alguns sentidos da formação universitária em Produção Cênica, como se houvesse uma receita eficaz para o que poderia se configurar como uma boa carreira de produtor: a relação com o tempo: "Até o sucesso chegar lá se foram uns dez ou quinze anos, hein...", a relação entre trabalho e estudo: "Trabalho + muito trabalho + estudo" e as relações com o outro: " $\mathrm{E}$ ainda tem a parte que $\mathrm{o}$ sucesso começa a incomodar, as máscaras a cair".

É interessante pensar que o sentido de trabalho do produtor, na ótica desses discentes, mesmo que esteja rodeado pelos brilhos de uma profissão que dialoga diretamente com o campo cultural e artístico, aparece nesse eixo de análise como um meio de sobrevivência, mesmo em dias nos quais o trabalho tem ganhado novas dimensões e configurações. É o que confirma o comentário do Sujeito 2, nos fazendo concordar com Bakhtin quando ele afirma que somos constituídos por vozes de diferentes pessoas e tempos: "[...] e bota comida na mesa, né gente [...]".

\section{Considerações finais}

Esta pesquisa se debruçou sobre a formação universitária, a partir de enunciados presentes na esfera virtual. A expectativa com relação à formação e à vida após a graduação aponta para as relações entre mercado e universidade. Esses são campos intrinsecamente ligados. É necessário, então, lançar mais questionamentos: 0 que é e como está o mercado de trabalho na esfera artística? A partir do discurso dos discentes, foi possível refletir sobre a preocupação com relação à carreira do produtor. Uma carreira que oscila entre o ofício de trabalho e a fama como resultado de um suposto sucesso: ainda há um abismo entre "a vitrine e a estante".

Apesar da problemática em torno da falta de apoio e de políticas mais eficazes relacionadas à cultura e à educação, acreditamos que o espaço universitário ainda é o melhor caminho para formar mais que profissionais, mas sujeitos pensantes, criadores e críticos que possam buscar alternativas para essas problemáticas, pois observamos, na análise, que os alunos não estão alheios à sua formação.

Outro fator que pode ser abordado a partir do resultado da investigação é que o profissional da produção cênica existe antes de uma formação universitária, configurando-se, portanto, em uma profissão em busca de identidade. Quando se fala em teatro, o primeiro profissional que vem à mente é o da atuação, entretanto, nada impede que um ator/atriz exerça, juntamente com a atuação, a 
produção cênica e um produtor também atue como ator/atriz.

Fato é que a história como o curso se configurou, incialmente como formador de ator, contribuiu para que essa memória permanecesse intrínseca no discurso de seus discentes. A questão que lançamos nessa conclusão, retoma um dos pontos discutidos na análise: qual formação universitária consegue imprimir em seus discentes uma sensação de completude quando esses se tornam egressos de seus cursos? Será que a falta ou a ausência de uma completude não é, por si só, constitutiva do próprio processo de formação?

Nesse sentido, atrelar esse estudo às ideias de Bakhtin e o Círculo foi, no percurso da pesquisa, um caminho de construção do qual não conseguimos mais fugir. Conceitos como dialogismo, alteridade, enunciado, sentidos, atitude responsiva, gêneros discursivos, puderam ampliar o olhar da pesquisa e dos pesquisadores para que fosse apresentado à área de conhecimento um trabalho aberto a possibilidades, mas não isento de resultados.

O Curso de Produção Cênica está inserido em um setor de Educação Profissional e Tecnológica, em que múltiplas linguagens dialogam. Pensando nisso, optar como lócus de pesquisa pela rede social Facebook foi um movimento dialógico que nos fez repensar as novas formas de leitura, escrita e pesquisa que vêm se apresentando na atualidade.

A rede social Facebook contém uma linguagem dimensional que integra palavras, sons, imagens e atos interativos (curtir, comentar, compartilhar). São postagens contando fatos cotidianos, recados de um para o outro ou outros, imagens do dia a dia, piadas, ironias, poesia, crônica, crítica, teatralidade, música, etc. Cremos que as redes sociais são a representação das interações nos dias atuais, que as quais como marca central a agilidade.

Se, por um lado, estamos tão conectados em uma rede de amigos, po outro, podemos sim nos sentir sozinhos, pois em meio à tecnologia, ainda somos humanos. Mas esse navegar por páginas de colegas e alunos do curso de graduação em Produção Cênica proporcionou encontros que nos constituíram.

Observando o material empírico resultante do trabalho de pesquisa, vemos quantos sentidos podem ainda ser explorados em outras investigações. Novas provocações, novos conflitos e ressignificações.

Como compreendemos que um texto é um processo inacabado e em permanente diálogo e que o aporte teórico tem uma amplitude que, mesmo explorada, ainda nos parece uma fonte inesgotável de conhecimento, incluimos nesse diálogo as palavras de Amorim (2004), que expressam com sensibilidade o ânimo do pesquisador em relação aos seus anseios a cada descoberta científica:

Toda pesquisa só tem um começo depois do fim. Dizendo melhor, é impossível saber quando e onde começa um processo de reflexão. Porém, uma vez terminado, é possível ressignificar o que veio antes e tentar ver indícios no que ainda não era e que passou a ser (AMORIM, 2004, p. 11). 


\section{University education into discourse on the Facebook social network: what say the Scenic Production students?}

\section{Abstract}

This paper presents some results of a research aimed to understand the meanings of university education in Scenic Production, from what they tell their students in the social network Facebook. Was chosen for this article a post, accompanied by statements present in the comments section. The theoretical and methodological approach is the Dialogic Discourse Analysis, which has in the studies of Bakhtin Circle her main theoretical grounding. The results show discourses on university education in Scenic Production related to concerns about a new area of knowledge and work, that amid the troubles and challenges of career, needs to be in tune with the cultural sphere. Another important note is the appropriation of the social network Facebook as a means of interaction and dialogue, reading and writing, deserving, so a watchful eye on the part of the academy.

Keywords: University education. Social network. Dialogic Discourse Analysis.

\section{Notas}

1 O pensamento bakhtiniano é o conjunto de formulações teóricas advindas dos estudos do Círculo de Bakhtin. Embora existam diferentes atribuições ao termo por parte de alguns pesquisadores, não faremos uma explanação explicativa e histórica, mas utilizaremos a expressão Bakhtin e o Círculo para fazer referência ao conjunto da obra que traz ideias produzidas por intelectuais russos desde a segunda década do século XX, entre os quais Mikhail Bakhtin
(1895-1975), Valentin N. Volochinov (18951936) e Pável N. Medviédev (1891-1938).

2 Em: <http://www.gazetadopovo.com.br/vidaecidadania/conteudo.phtml?id=871930 $>$. Acesso em: 3 jul. 2014.

\section{Referências}

AMORIM, Marilia. O Pesquisador e seu Outro: Bakhtin nas Ciências Humanas. São Paulo: Editora Musa, 2004.

BAKHTIN, Mikhail. (VOLOSHINO V, V. N.). Marxismo e filosofia da linguagem: problemas fundamentais do método sociológico na ciência da linguagem. Tradução para a Língua Portuguesa: Michel Sahud e Yara Frateschi Vieira; 13 ed. São Paulo: Hucitec, 2009.

Estética da Criação Verbal. Tradução do russo: Paulo Bezerra. 6. ed. São Paulo: Ed Martins Fontes, 2011.

. Questões de literatura e estética. A teoria do romance. Tradução do russo: Aurora Fornoni Bernardini, José Pereira Júnior, Augusto Góes Júnior, Helena Spryndis Nazário, Homero Freitas de Andrade; 6. ed. São Paulo: Hucitec, 2010.

BALEIRO, Zeca. A rede idiota. São Paulo: Reformatório, 2014.

BRAIT, Beth. Perspectiva dialógica. In: BRAIT, Beth; SOUZA-e-SILVA, Maria Cecília. Texto ou Discurso? São Paulo: Contexto, 2012. p. 9-30.

Beth. Ironia em perspectiva polifônica. Campinas: Unicamp, 2008.

BRASIL. Ministério da Educação. Secretaria de Educação Profissional e Tecnológica. Catálogo Nacional de Cursos Superiores. Brasília, DF: Ministério da Educação, 2010. 73 p. Disponível em: <http://portal.mec.gov.br/ index.php?option $=$ com_docman\&task $=$ doc download\&gid $=5362 \&$ Itemid $=>$. Acesso em: 3 jul. 2014. 
- Ministério da Educação. Projeto Político Pedagógico do curso de Graduação Tecnológica em Produção Cênica. Curitiba, Universidade Federal do Paraná. Setor de Educação Profissional e Tecnológica, 2012. 173 p. Disponível em: <http://www.sept. ufpr.br/producaocenica.html>. Acesso em: 10 jun. 2014.

BUARQUE, Cristovam. A aventura da universidade. São Paulo: Editora Unesp, 1993.

CAMPOS, Maria Malta. Para que serve a pesquisa em Educação? Caderno de Pesquisa, São Paulo, v. 39, n. 136, p. 269-283, jan./ abr. 2009.

CANCLINI, Néstor García. Leitores, espectadores e internautas. São Paulo: Iluminuras Ltda, 2008.

CASTELLS, Manuel. A sociedade em rede. São Paulo: Paz e Terra, 2000.

CASTRO, Gilberto. Discurso citado e memória: ensaio bakhtiniano sobre Infância e São Bernardo. Chapecó: Argos, 2014.

COELHO, Teixeira. Dicionário crítico de política cultural: cultura e imaginário. São Paulo: Iluminuras Ltda, 1997.

EAGLETON, Terry. A idéia de cultura. 2 . ed. Tradução de Sandra Castello Branco. São Paulo: Unesp, 2011.

FLICK, Uwe. Uma introdução à pesquisa qualitativa. Porto Alegre: Bookman, 2004

FREITAS, Maria Tereza. A abordagem Sócio-histórica como orientadora da pesquisa qualitativa. In: Cadernos de Pesquisa. São Paulo, n. 116, p. 21-39, jul. 2002.

GHELLI, Guilherme. A construção do saber no ensino superior. Cadernos da Fucamp, Monte Carmelo, v. 3, n. 3, jul. 2004.

MARTINHO, Cassio. Redes. 2011. Disponível em: <http://www.redescomunitarias.org.br/ images/Biblioteca/Redes.pdf $>$. Acesso em 22 jan. 2015.
OLIVIERI, Cristiane; NATALE, Edson. Guia Brasileiro de Produção Cultural. São Paulo: Edições Sesc, 2010

SMIERS, Joost. Artes sob Pressão - promovendo a diversidade cultural na era da globalização. São Paulo: Escrituras, 2006. 